\title{
SENSIBILIDADE E ESPECIFICIDADE DO “CALIFORNIA MASTITIS TEST" COMO RECURSO DIAGNÓSTICO DA MASTITE SUBCLÍNICA EM RELAÇÃO À CONTAGEM DE CÉLULAS SOMÁTICAS ${ }^{1}$
}

\author{
José Renaldi Feitosa Brito ${ }^{2}$, George Afonso Vitor Caldeira ${ }^{3}$, Rui da Silva Verneque ${ }^{2}$ e \\ Maria Aparecida Vasconcelos Paiva e Brito ${ }^{2}$
}

\begin{abstract}
Brito J. R. F., Caldeira G. A. V., Verneque R. S. \& Brito M. A. V. P. 1997. [Sensitivity and specificity of the California Mastitis Test as a diagnostic tool for subclinical mastitis in quarter somatic cell count estimation.] Sensibilidade e especificidade do "California Mastitis Test" como recurso diagnóstico da mastite subclínica em relação à contagem de células somáticas. Pesquisa Veterinária Brasileira 17(2):49-53. Embrapa - Centro Nacional de Pesquisa de Gado de Leite, Rodovia MG 133, km 42, Coronel Pacheco, MG 36155-000, Brazil.

The California Mastitis Test (CMT) is a simple and widely used diagnostic tool for subclinical mastitis. It is used even in areas where laboratory facilities are available for diagnosis and monitoring program purposes. CMT usually score $1-5$, where 1 indicates a completely negative reaction and 2-5 increasing degrees of inflammatory reaction of the udder. The reactions 2-5, 3-5 or 4-5 may be considered as indicative of subclinical mastitis, because they are related to an increase of the somatic cell count (SCC) in the milk. This variation, however, may produce either false-positive or false-negative results. The aim of this study was to assess the sensitivity and specificity of the CMT in comparison with SCC. A total of 3,012 quarter milk samples from 760 lactating cows were examined. CMT was evaluated at the moment of sampling at cow side and SCC in the laboratory, with a fluoro-opto-electronic method (Fossomatic 90). The average CCS (x 1,000 cells/ml) for CMT scores were: 1 (79.9), 2 (333.5), 3 (670.3), 4 $(1,354.0)$ and $5(4,455.6)$. Three options for CMT interpretation were evaluated in relation to a range of CCS, starting from 100,000 cells/ml: (a) 1 versus 2, 3, 4, and 5; (b) 1 and 2 versus 3, 4 and 5; and (c) 1, 2 and 3 versus 4 and 5 . The sensitivities of CMT scoring to detect quarters with SCC $>200,000 / \mathrm{ml}$ were $79 \%, 61 \%$ e $34 \%$ for options $a, b$ and $c$, respectively. The sensitivities of CMT scores for SCC $>500,000 / \mathrm{ml}$ for options $a, b$ and $c$, were, respectively, $93 \%, 82 \% \mathrm{e}$ $54 \%$. The sensitivity of CMT scores to identify subclinical mastitis was satisfactory (above $80 \%$ ) when options $b$ and $c$ were used. The interpretation of CMT score 3 as negative for subclinical mastitis was considered as adequate (sensitivity around $80 \%$ ) only when CCS ranged between $1,200,000$ and $1,400,000$ cells $/ \mathrm{ml}$. The specificities of CMT scoring for CCS of 200,000 and 500,000 were, respectively, $90 \%$ and $80 \%$ (option $a$ ), $97 \%$ and $90 \%$ (option $b$ ) and $99 \%$ and $97 \%$ (option c).
\end{abstract}

INDEX TERMS: Dairy cows, somatic cell count, milk, mammary gland.

\footnotetext{
${ }^{1}$ Aceito para publicação em 21 de fevereiro de 1997.

Realizado com apoio financeiro do Conselho Nacional de Desenvolvimento Científico e Tecnológico (CNPq, Projeto 530.190/93-1).

2 Pesquisadores da Embrapa-CNPGL, Rodovia MG 133, km 42, Coronel Pacheco, MG 36155-000. Bolsistas do CNPq; e-mail do primeiro autor: kbrito@artnet.com.br.

${ }^{3}$ Médico-Veterinário, bolsista do CNPq.
}

SINOPSE.- O “California Mastitis Test” (CMT) estima o conteúdo de células somáticas no leite e é interpretado subjetivamente, estabelecendo-se escores que, na maioria dos casos, variam de 1 a 5 . 0 escore 1 indica uma reação completamente negativa e os de 2-5 indicam graus crescentes de resposta inflamatória do úbere, sendo normalmente considerados como indicativos de mastite subclínica. Dependendo da in- 
terpretação dos escores, o CMT pode produzir resultados falso-positivos ou falso-negativos. Esse trabalho teve o objetivo de avaliar a sensibilidade e a especificidade do CMT em relação à contagem de células somáticas (CCS). Foram utilizadas 3.012 amostras de leite provenientes de 760 vacas Holandesas ou mestiças Holandês-Zebu, pertencentes a 15 rebanhos. Todas as amostras foram submetidas ao CMT e processadas para CCS em equipamento Fossomatic 90. Os valores médios de CCS (x 1.000 células/ml) obtidos para os escores de CMT foram $1(79,9), 2(333,5), 3(670,3), 4(1.354,0)$ e $5(4.455,6)$. Três opções de interpretação (doente/não-doente) para o CMT foram testadas, em relação aos valores de CCS, iniciando com 100.000 células/ml: (a) 1 versus $2,3,4$, e 5; (b) 1 e 2 versus 3 , 4 e 5 ; (c) 1, 2, 3 versus 4 e 5 . As sensibilidades do CMT em identificar corretamente quartos mamários acima de 200.000 células/ml foram $79 \%, 61 \%$ e $34 \%$, para as opções $a, b$ e $c$, respectivamente. Para identificar corretamente contagens acima de 500.000 células/ml, as sensibilidades do CMT, para as opções $a, b$ e $c$, foram, respectivamente: $93 \%, 82 \%$ e $54 \%$. A sensibilidade do CMT em identificar quartos mamários com mastite subclínica foi adequada (acima de $80 \%$ ) quando a interpretação do teste foi mais rigorosa (opções $a$ e $b$ ). A interpretação da reação 3 como negativa (opção $c$ ) só alcançou sensibilidade de $80 \%$ para contagens entre 1.200 .000 e 1.400 .000 células/ml. As especificidades do CMT, para CCS de 200.000 e 500.000 foram, respectivamente, $90 \%$ e $80 \%$ (opção a), $97 \%$ e $90 \%$ (opção b) e $99 \%$ e $97 \%$ (opção c).

TERMOS DE INDEXAÇÃO: Vacas leiteiras, contagem de células somáticas, leite, glândula mamária.

\section{INTRODUÇÃO}

A mastite é definida como uma reação inflamatória da glândula mamária e, de acordo com a causa ou principal causa da inflamação, pode ser classificada como infecciosa, traumática ou tóxica (IDF 1987). As infecções da glândula mamária provocam redução da produção e da mudança da composição do leite que variam de acordo com a intensidade e a duração das infeç̧ões. A mastite pode se manifestar na forma clínica ou subclínica (Bramley et al. 1996). Na forma subclínica, ao contrário da forma clínica, não ocorrem mudanças visíveis na aparência do leite ou do úbere, embora ocorram alterações na composição do leite e deste possam ser isolados microrganismos patogênicos (Bramley et al. 1996). A mastite subclínica tem grande impacto na produtividade dos rebanhos leiteiros porque sua prevalência é maior que a da forma clínica (Philpot \& Nickerson 1991) e, assim, as medidas para o seu controle têm recebido grande atenção.

A invasão da glândula mamária por microrganismos é seguida de um aumento do número de leucócitos no leite, a maioria, neutrófilos polimorfonucleares (Burvenich et al. 1995). Essas células fazem parte dos mecanismos naturais de defesa do animal, migram da corrente circulatória para a glândula mamária e são designadas de células somáticas do leite. 0 principal fator que influencia o aumento das células somáticas no leite é o estado infeccioso (Harmon 1994). Ou- tros fatores como estádio de lactação, idade do animal, estação do ano e vários tipos de estresse podem influenciar a contagem de células somáticas (CCS) mas não têm tanta importância se não ocorre infecção da glândula mamária (Reneau 1986, Harmon 1994).

Os métodos de diagnóstico da mastite subclínica incluem exames microbiológicos, métodos químicos indiretos e a CCS do leite dos quartos mamários individuais, dos animais ou do rebanho (Quinn et al. 1994). O "California Mastitis Test" (CMT) é usado mundialmente para o diagnóstico da mastite subclínica, tendo a vantagem de poder ser empregado no próprio rebanho, no momento em que os animais são ordenhados. A interpretação do CMT se baseia na observação visual do leite após ser misturado ao reagente. A reação se processa entre o reagente e o material genético das células somáticas presentes no leite, formando um gel, cuja concentração é proporcional ao número de células somáticas. $O$ resultado do CMT é dado como negativo, suspeito, fracamente positivo, positivo e fortemente positivo (Schalm \& Noorlander 1957). Os escores do CMT apresentam correlações variadas com a CCS (Philpot \& Nickerson 1991, Quinn et al. 1994). Tem-se questionado a interpretação do CMT como instrumento de diagnóstico da mastite subclínica, por ser um teste subjetivo que produz resultados falso-positivos ou falso-negativos, e considerando-se a definição de "doença" em função dos mesmos parâmetros adotados para a CCS (Martin et al. 1994, Casura et al. 1995).

Este trabalho teve o objetivo de avaliar a sensibilidade e a especificidade do CMT em relação à contagem eletrônica de células somáticas do leite de vacas mantidas sob as condições da região da Zona da Mata de Minas Gerais.

\section{MATERIAL E MÉTODOS}

Foram examinadas amostras de leite de 760 vacas da raça Holandesa (7 rebanhos) e mestiças Holandês-Zebu (8 rebanhos). O CMT foi realizado imediatamente após a preparação higiênica do úbere para a ordenha e o descarte e exame dos primeiros jatos de leite (Philpot $\&$ Nickerson 1991). 0 reagente do CMT foi preparado com detergente comercial, de acordo com Langenegger et al. (1970). As reações foram interpretadas de acordo com Philpot \& Nickerson (1991) com anotação dos escores de 1 a 5 , onde 1 indicou uma reação completamente negativa; 2: reação suspeita (traços); 3: reação fracamente positiva; 4: reação positiva e 5: reação fortemente positiva (Enevoldsen et al. 1995).

Ao mesmo tempo em que era realizado o CMT, as amostras de leite foram colhidas em frasco com dicromato de potássio (1\%) e enviadas ao laboratório, sob refrigeração, para CCS, pelo método fluoro-opto-eletrônico, em equipamento Fossomatic 90. A metodologia empregada, os reagentes utilizados e a preparação e leitura das amostras seguiram as recomendações do IDF (1991).

Os resultados do CMT foram analisados quanto à sensibilidade e especificidade para diagnóstico da mastite subclínica, comparandoos com a CCS, de acordo com Erdreich \& Lee (1981). As conceituações de sensibilidade e especificidade foram feitas de acordo com Martin et al. (1994), que consideram a sensibilidade de um teste como sua habilidade de detectar animais doentes e é definida como a proporção (P) de animais doentes (d) que testam positivamente (D) $[P(D / d)]$. A especificidade de um teste é a sua habilidade de detectar 
animais não doentes e é definida como a proporção de animais nãodoentes $(\mathrm{n})$ que testam negativamente $(\mathrm{N})[\mathrm{P}(\mathrm{N} / \mathrm{n})]$. Para a construção da matriz de resultados da CCS dividiram-se os dados em intervalos de 100.000 células. Consideraram-se as contagens de 200.000 e de 500.000 células $/ \mathrm{ml}$ como pontos críticos para separação dos quartos mamários não-doentes daqueles com mastite subclínica (IDF 1987). Em relação ao CMT, foram avaliadas três opções para esta separação: (a) escore 1 versus 2,3 , 4 e 5 ; (b) escores 1 e 2 , versus 3 , 4 e 5 ; e (c) escores 1,2 e 3 versus 4 e 5 .

\section{RESULTADOS}

Do total de 3.016 amostras de leite, provenientes de igual número de quartos mamários, examinadas pelo CMT, quatro amostras, sendo uma com reação relativa ao escore 1 , uma com reação do escore 2 e duas com reações do escore 4 , foram eliminadas da análise porque suspeitou-se de troca de amostra por ocasião do processamento no laboratório ou identificação equivocada no momento da coleta. As análises dos dados foram realizadas com as 3.012 amostras restantes. O número e a proporção em que as reações do CMT ocorreram são apresentados no Quadro 1. Dependendo da inter-

Quadro 1. Distribuição das amostras de leite em função dos escores do "California Mastitis Test” (CMT)

\begin{tabular}{ccc}
\hline Escores & $\begin{array}{c}\text { Número } \\
\text { de amostras }\end{array}$ & Percentual \\
\hline 1 & 2.029 & 67,36 \\
2 & 313 & 10,39 \\
3 & 311 & 10,33 \\
4 & 237 & 7,87 \\
5 & 122 & 4,05 \\
Total & 3.012 & 100,00
\end{tabular}

pretação dos escores do CMT para avaliar os índices de mastite subclínica, obtiveram-se as seguintes proporções: $11,92 \%$ (considerando-se positivos apenas os escores 4 e 5); 22,25\% (para os escores positivos 3, 4 e 5); e 32,64\% (para os escores positivos 2, 3, 4 e 5).

De acordo com a CCS as amostras foram classificadas em oito estratos, cujas frequências encontram-se no Quadro 2. Considerando os limites de 200.000 e 500.000 células $/ \mathrm{ml}$, as proporções de quartos mamários com mastite subclínica foram 32,93\% e $17,73 \%$, respectivamente. A relação entre os escores do CMT e a CCS é apresentada no Quadro 3. O valor médio (x 1.000 células/ml) obtido para a reação negativa (escore 1) do CMT foi 79,88. O escore 2 correspondeu a 333,51. Para os escores 3, 4 e 5, os valores médios foram, respectivamente, 670,33, 1.353,97 e 4.455,60.

As sensibilidades do CMT em relação aos diversos valores de CCS são apresentadas no Quadro 4. Para a CCS de 200.000/ $\mathrm{ml}$, as sensibilidades do CMT foram $79 \%, 60 \%$ e $34 \%$, para as opções a, b e c, respectivamente. As especificidades do CMT para os mesmos casos foram, respectivamente, $90 \%, 97 \% \mathrm{e}$ 100\% (Quadro 4).

A sensibilidade do CMT manteve-se acima de $90 \%$ no caso da opção a, a partir da contagem de 400.000 células/ml. Pa-ra a opção b, a sensibilidade variou de aproximadamente $80 \%$ (CCS 500.000 ) a $90 \%$, ou mais, a partir da CCS de $800.000 / \mathrm{ml}$. Para a opção c a sensibilidade foi de $54 \%$ (CCS de $500.000 / \mathrm{ml}$ ), só alcançando sensibilidade de cerca de $80 \%$ quando a CCS selecionada foi entre 1.200 .000 e $1.400 .000 / \mathrm{ml}$ (Quadro 4).

\section{DISCUSSÃO}

A determinação da CCS no leite é um método convencional e amplamente usado para o diagnóstico da mastite subclínica

Quadro 2. Distribuição das amostras de leite de acordo com a contagem de células somáticas (CCS)

\begin{tabular}{lcccc}
\hline Intervalos de CCS & Frequencia & $\begin{array}{c}\text { Frequencia } \\
\text { acumulada }\end{array}$ & $\begin{array}{c}\text { Frequencia } \\
\text { relativa }\end{array}$ & $\begin{array}{c}\text { Frequencia rela- } \\
\text { tiva acumulada }\end{array}$ \\
\hline Até 100.000 & 1.658 & 1.658 & 55,05 & 55,05 \\
100.001 a 200.000 & 362 & 2.020 & 12,02 & 67,07 \\
200.001 a 400.000 & 358 & 2.378 & 11,89 & 78,95 \\
400.001 a 500.000 & 100 & 2.478 & 3,32 & 82,27 \\
500.001 a 1.000 .000 & 236 & 2.714 & 7,84 & 90,11 \\
1.000 .001 a 2.000 .000 & 153 & 2.867 & 5,08 & 95,19 \\
2.000 .001 a 4.000 .000 & 73 & 2.940 & 2,42 & 97,61 \\
Acima de 4.000 .001 & 72 & 3.012 & 2,39 & 100,00
\end{tabular}

Quadro 3. Contagem de células somáticas (CCS) de 3.012 amostras de leite, distribuídas entre diferentes classes de escores do "California Mastitis Test" (CMT)

\begin{tabular}{cccccc}
\hline \multirow{2}{*}{$\begin{array}{c}\text { Escores } \\
\text { do CMT }\end{array}$} & \multirow{2}{*}{$\begin{array}{c}N^{\circ} \text { de } \\
\text { amostras }\end{array}$} & Mínimo & Máximo & Média & \multirow{2}{*}{ Erro padrão } \\
\cline { 3 - 5 } & 2.029 & 1,0 & 3.438 & 79,88 & \\
\hline 1 & 313 & 4,0 & 2.453 & 333,51 & 2,93 \\
3 & 311 & 10,0 & 4.409 & 670,33 & 34,04 \\
4 & 237 & 11,0 & 8.701 & $1.353,97$ & 84,08 \\
5 & 122 & 18,0 & 10.000 & $4.455,60$ & 300,50
\end{tabular}


Quadro 4. Sensibilidade e especificidade do "California Mastitis Test" (CMT) para identificação de quartos mamários com mastite subclínica, para diferentes contagens de células somáticas (CCS), considerando-se três interpretações para as reações do CMT na conceituação de "não doente" versus "doente"

\begin{tabular}{ccccccc}
\hline CCS & $\begin{array}{c}\text { CMT 1 vs. } \\
\text { Sensibilidade }\end{array}$ & $\begin{array}{c}\text { 2, 3, 4 e 5 } \\
\text { Especificidade }\end{array}$ & $\begin{array}{c}\text { CMT 1 e 2 vs. } \\
\text { Sensibilidade }\end{array}$ & $\begin{array}{c}\text { 3, 4 e 5 } \\
\text { Especificidade }\end{array}$ & $\begin{array}{c}\text { CMT 1, 2 e 3 } \\
\text { Sensibilidade }\end{array}$ & $\begin{array}{c}\text { vs. 4 e 5 } \\
\text { Especificidade }\end{array}$ \\
\hline 100 & 0,66 & 0,95 & 0,48 & 0,99 & 0,26 & 1,00 \\
200 & 0,79 & 0,90 & 0,61 & 0,97 & 0,34 & 0,99 \\
400 & 0,92 & 0,83 & 0,78 & 0,93 & 0,48 & 0,98 \\
500 & 0,93 & 0,80 & 0,82 & 0,91 & 0,54 & 0,97 \\
600 & 0,95 & 0,79 & 0,86 & 0,89 & 0,58 & 0,97 \\
800 & 0,96 & 0,76 & 0,90 & 0,87 & 0,66 & 0,96 \\
1.000 & 0,97 & 0,74 & 0,93 & 0,85 & 0,73 & 0,95 \\
1.200 & 0,98 & 0,73 & 0,95 & 0,84 & 0,78 & 0,94 \\
1.400 & 0,99 & 0,72 & 0,98 & 0,83 & 0,84 & 0,93 \\
1.500 & 0,99 & 0,72 & 0,97 & 0,83 & 0,84 & 0,93 \\
2.000 & 1,00 & 0,71 & 0,99 & 0,82 & 0,90 & 0,92 \\
2.500 & 1,00 & 0,70 & 1,00 & 0,81 & 0,94 & 0,91
\end{tabular}

em regiões de pecuária leiteira desenvolvida. É também o parâmetro mais empregado para avaliação da qualidade higiênica do leite, além de ser um instrumento valioso para avaliação e monitorização da mastite nos rebanhos (Heeschen \& Reichmuth 1995). Três procedimentos são descritos pela "International Dairy Federation" (IDF 1991) para a enumeração de células somáticas: um microscópico e dois automáticos que utilizam os equipamentos "Coulter Counter" e "Fossomatic". Mesmo nas regiões onde os métodos automatizados são disponíveis, o CMT continua a ser um instrumento importante para avaliação de quartos mamários individuais, pelas vantagens de fornecer resultados imediatos, ser prático e ter baixo custo (Casura et al. 1995, Enevoldsen et al. 1995). Essas vantagens foram confirmadas no presente trabalho. O CMT apresenta, entretanto, $o$ inconveniente da subjetividade e, por não ser patognomônico, sujeito a produzir resultados falso-positivos e falso-negativos (Martin et al. 1994). Para contornar esses problemas, temse proposto tabelas onde são apresentados os valores de CCS em relação aos escores de CMT (NMC 1987, Philpot \& Nickerson 1991). Os valores médios de CCS em relação aos escores de CMT, especialmente com relação às reações 1 (negativa), 2 (suspeita) e 3 (fracamente positiva), obtidos no presente trabalho, são similares aos dos trabalhos citados (NMC 1987, Philpot \& Nickerson 1991). Os valores médios de CCS obtidos para os escores de CMT 4 e 5 , entretanto, foram abaixo das médias obtidas por aqueles autores. Essas diferenças podem ser explicadas em função da subjetividade característica do CMT, da diferença entre reagentes utilizados e, ainda, devido a prováveis diferenças tanto metodológicas quanto dos equipamentos utilizados para a CCS. Os dados obtidos neste trabalho, entretanto, apresentam maior amplitude, quando comparados aos dados apresentados (NMC 1987), comprovando a subjetividade da interpretação do CMT (Quadro 3).

A definição de não-doente ou não-infectado, em relação à CCS, tem variado desde cerca de 100.000 células $/ \mathrm{ml}$ até 500.000/ml (Reneau 1986, IDF 1991, Harmon 1994, Casura et al. 1995, Heeschen $\&$ Reichmuth 1995). O limite de 500.000 células/ml utilizado para separação entre não-doente ou nãoinfectado e doente ou infectado, embora adotado por muitos autores (IDF 1987, Casura et al. 1995) pode ser, ainda, considerado elevado (Reneau 1986, Vecht et al. 1989, 1990). Para aumentar a sensibilidade do CMT em identificar quartos mamários com contagens de células acima dos parâmetros normais, os dados obtidos apontam a necessidade de se considerar os escores 3, 4 e 5 como indicativos de mastite subclínica. Considerando-se positivas apenas as reações $4 \mathrm{e}$ 5 , a sensibilidade do CMT para detectar quartos mamários com contagens acima de 500.000 células/ml foi de aproximadamente $54 \%$, enquanto que, considerando-se positivas as reações 3,4 e 5 , a sensibilidade do teste aumentou para $82 \%$. Além disso, quando se consideraram positivos apenas os escores 4 e 5 , a sensibilidade de cerca de $80 \%$ só foi observada a partir das contagens entre 1.200 .000 e 1.400 .000 células/ $\mathrm{ml}$.

A tendência internacional em termos de qualidade do leite é o aumento da exigência na redução da CCS (Heeschen \& Reichmuth 1995). Os dados apresentados no Quadro 4 mostram que à medida que é aumentada a exigência em termos de CCS, aumenta a necessidade de interpretar o CMT com maior rigor, uma vez que quando se reduz o limite crítico para 400.000 células, a sensibilidade da opção $c$ é reduzida para apenas $48 \%$, comparada a $92 \%$ e $78 \%$, para as opções $a$ e $b$, respectivamente.

Os resultados obtidos com os testes de especificidade comprovam os dados obtidos por Casura et al. (1995) e são justificados por Martin et al. (1994), que demonstraram ser a especificidade mais alta à medida que o limite crítico é definido menos rigidamente.

Outras vantagens do uso do CMT são possibilitar a identificação de animais sob risco, selecionar amostras para exame laboratorial e servir de base para a organização de linhas de ordenha em rebanhos comprometidos (Philpot \& Nickerson 1991). O uso regular do CMT pode contribuir para melhorar o estado sanitário dos rebanhos, se os dados obtidos forem usados para orientar a adoção de medidas para o controle da mastite e se forem associadas práticas adequa- 
das de manejo e higiene. Contudo, dependendo da interpretação dada ao teste, pode-se colocar em risco programas de controle da doença pela possibilidade de se identificar um número considerável de animais ou quartos mamários doentes como normais. Como tem sido comprovada uma correlação positiva entre animais reagentes ao CMT e a presença de infeç̧ão, mesmo para as reações consideradas suspeitas (Figueiredo 1962, Langenegger et al. 1970, Harrop et al. 1975), a utilização do CMT, com base nos escores 4 e 5 , para selecionar animais para exame microbiológico ou para a organização de linha de ordenha, fica também comprometida.

Agradecimentos.- À Christian Hansen Indústria e Comércio Ltda, pela doação de reagentes e empréstimo do equipamento Fossomatic 90.

\section{REFERÊNCIAS}

Bramley A. J., Cullor J. S., Erskine R. J., Fox 1. K., Harmon R. J., Hogan J. S., Nickerson S. C., Oliver S. P., Smith K. L. \& Sordillo 1. M. 1996. Current concepts of bovine mastitis. National Mastitis Council, Madison, p. 1-3.

Burvenich C., Guidry A. J. \& Paape M.J. 1995. Natural defence mechanisms of the lactating and dry mammary gland. Proc. IDF Int. Mastitis Seminar, Tel Aviv, p. 1.3-1.13.

Casura C., Schukken Y. H. \& Rüsch P. 1995. Quality assessment of California mastitis test as a diagnostic tool in quarter somatic cell count estimation. Proc. IDF Int. Mastitis Seminar, Tel Aviv, p. 3.57-3.58.

Enevoldsen C., Grohn Y. T. \& Thysen I. 1995. Dairy cow characteristics related to Staphylococcus aureus isolation from quarter samples. J. Dairy Res. 62: 69-81.

Erdreich L. S. \& Lee E. T. 1981. Use of relative operating characteristic analysis in epidemiology. A method for dealing with subjective judgment. Am. J. Epidemiol. 114: 649-662.

Figueiredo J. B. 1962. Estudo sobre a mamite bovina no município de Betim, Minas Gerais. Arqs Esc. Vet. UFMG, Belo Horizonte, 14: 257-295.
Harmon R. J. 1994. Physiology of mastitis and factors affecting somatic cell counts. J. Dairy Res. 77: 2103-2112.

Harrop M. H. V., Pereira L. J. G., Brito J. R. F. \& MELLO A. M. B. 1975. Incidência de mastite bovina na bacia leiteira da Zona do Agreste Meridional de Pernambuco. Pesq. Agropec. Bras., Série Vet., 10: 65-67.

Heeschen W. \& Reichmuth J. 1995. Mastitis: influence on qualitative and hygienic properties of milk. Proc. IDF Int. Mastitis Seminar, Tel Aviv, p. 3.33.13 .

International Dairy Federation 1987. Bovine mastitis: definition and guidelines for diagnosis. IDF Bulletin 211. 24p.

International Dairy Federation 1991. Milk. Enumeration of somatic cells. IDF Standard 148. 8p.

Langenegger J., Coelho N. M., Langenegger C. H. \& Castro R. P. 1970. Estudo da incidência da mastite bovina na bacia leiteira do Rio de Janeiro. Pesq. Agropec. Bras., Série Vet., 5: 437-440.

Martin S. W., Meek A. H. \& Willeberg P. 1994. Measurement of disease frequency and production, p. 48-76. In: Martin S. W., Meek A. H. \& Willeberg P. (ed.) Veterinary Epidemiology. Principles and Methods. Iowa State University Press, Ames.

Philpot W. N. \& Nickerson S. C. 1991. Mastitis: counter attack. Babson Bros, Naperville. 150p.

Quinn P. J., Carter M. E., Markey B. K. \& Carter G. R. 1994. Mastitis, p. 327344. In: Quinn P. J., Carter M. E., Markey B. K. \& Carter G. R. (ed.) Clinical Veterinary Microbiology. Wolfe Publishing, London.

Reneau J. K. 1986. Effective use of dairy herd improvement somatic cell counts in mastitis control. J. Dairy Sci. 69: 1708-1720.

Schalm O. W. \& Noorlander D. D. 1957. Experiments and observations leading to development of the California Mastitis Test. J. Am. Vet. Med. Assoc. 130: 199-204.

Vecht U. \& Wisselink H. J. 1990. Dutch national mastitis survey. The value of bulk milk cell counts in diagnosing bovine mastitis. Neth. Milk Dairy J. 44: 83-88.

Vecht U., Wisselink H. J. \& Defize P. R. 1989. Dutch national mastitis survey. The effect of herd and animal factors on somatic cell count. Neth. Milk Dairy J. 43: 425-435. 